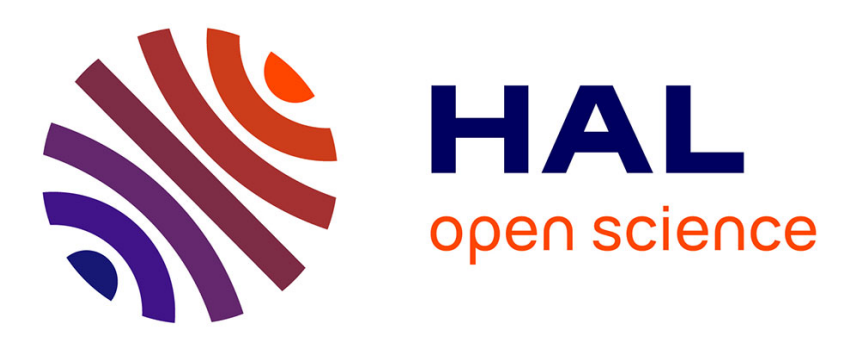

\title{
Photovoltaic effect in InSe - Application to Solar Energy Conversion
}

\author{
A. Segura, J.P. Guesdon, J.M. Besson, A. Chevy
}

\section{To cite this version:}

A. Segura, J.P. Guesdon, J.M. Besson, A. Chevy. Photovoltaic effect in InSe - Application to Solar Energy Conversion. Revue de Physique Appliquée, 1979, 14 (1), pp.253-257. 10.1051/rphysap:01979001401025300 . jpa-00244584

\section{HAL Id: jpa-00244584 https://hal.science/jpa-00244584}

Submitted on 1 Jan 1979

HAL is a multi-disciplinary open access archive for the deposit and dissemination of scientific research documents, whether they are published or not. The documents may come from teaching and research institutions in France or abroad, or from public or private research centers.
L'archive ouverte pluridisciplinaire HAL, est destinée au dépôt et à la diffusion de documents scientifiques de niveau recherche, publiés ou non, émanant des établissements d'enseignement et de recherche français ou étrangers, des laboratoires publics ou privés. 


\title{
Photovoltaic effect in InSe Application to Solar Energy Conversion
}

\author{
A. Segura, J. P. Guesdon, J. M. Besson \\ Laboratoire de Physique des Solides $\left(^{*}\right)$ \\ and A. Chevy \\ Laboratoire de Luminescence (*), 4, place Jussieu, Paris Ve, France \\ (Reçu le 28 juillet 1978, révisé le 9 octobre 1978, accepté le 11 octobre 1978)
}

\begin{abstract}
Résumé. - Les propriétés de transport d'InSe $\mathrm{n}$ et $\mathrm{p}$ ont été mesurées, ainsi que les paramètres des porteurs photoexcités. La fabrication des diodes p-n et Schottky est décrite. Les spectres photovoltaïques sont comparés avec les valeurs mesurées des paramètres optiques et de transport. Les caractéristiques d'InSe pour la conversion de l'énergie solaire, et le rendement des photopiles sont discutés.
\end{abstract}

Abstract. - The transport properties of indium monoselenide have been measured in n- and p-type material. Parameters for photoexcited carriers are given. Fabrication procedures for Schottky and p-n diodes are reported. Photovoltaic spectra are fitted with measured values of transport and optical parameters. InSe is shown to be a new material with attractive characteristics for solar energy conversion. Performance of InSe solar cells is discussed.

1. Introduction. - Indium monoselenide is a layer semiconductor. It belongs to the homogeneous family of In-Ga chalcogenides but has been much less studied than gallium sulfide or selenide for example. Its lamellar structure is similar to $\gamma$-GaSe $\left(C_{3 v}\right.$ point group) and the anisotropy of mechanical properties is higher than in $\mathrm{GaS}$ or $\mathrm{GaSe}$.

The energy gap of InSe is about $1.3 \mathrm{eV}$ at $300 \mathrm{~K}$ and it is thus close to the theoretical optimum for solar energy conversion. Since its transport properties show high mobilities $\left(10^{2}\right.$ to $10^{3} \mathrm{~cm}^{2} / \mathrm{V}$.s perpendicular to the $c$-axis) we have investigated its possibilities as a material for photovoltaic cells.

Transport in indium selenide shows a large anisotropy of mobilities parallel and perpendicular to the $c$-axis [1-6]. Photoconductivity studies [2, 7-11] have shown the presence of impurity centers and carrier traps which are responsible for anomalous conductivity and photomemory phenomena. Photovoltaic properties have not yet been intensively investigated $[12,13]$. Preliminary results $[13]$ on InSe-Bi heterostructures have been reported and shown interesting phototransport behaviour. We have fabricated InSemetal heterostructures and p-n junctions with much higher conversion efficiency than in reference [13].

In this paper we report briefly the transport properties of the bulk material we studied, then describe

(*) Associés au C.N.R.S. the fabrication procedures and photoelectronic parameters of homo- and hetero-junctions, then show that the overall efficiency of InSe junctions will compare with that of classical devices.

2. Transport properties of bulk material. - Bridgman - grown samples were prepared by methods described previously [14]. Unintentionally doped material was $\mathrm{n}$-type. Chlorine was used for $\mathrm{n}$-type doping, zinc or cadmium for p-type (Table I). Indium contacts were deposited by evaporation and heated to $300{ }^{\circ} \mathrm{C}$ under argon for up to $2 \mathrm{~h}$. This type of contact has satisfactory ohmicity on both types of InSe.

Hall effect was measured for directions perpendicular to the $c$-axis (in the layer plane) and results are summarized in table I.

Table I. - Transport characteristics of various substrates used for the fabrication of photovoltaic devices. For the discussion of Hall effect data, see text.

\begin{tabular}{|c|c|c|c|c|}
\hline $\begin{array}{l}\text { Sample } \\
\text { reference }\end{array}$ & $\begin{array}{l}\text { Doping } \\
\text { agent }\end{array}$ & Type & $\begin{array}{c}\text { Mobility } \perp c \\
\mathrm{~cm}^{2} / \text { V.s } 300 \mathrm{~K}\end{array}$ & $\begin{array}{c}\text { Carrier } \\
\text { concentration } \\
\text { n or p-cm } \\
300 \mathrm{~K}\end{array}$ \\
\hline - & - & - & - & - \\
\hline $364-11$ & none & $\mathrm{n}$ & $500-700$ & $2 \times 10^{15}$ \\
\hline $393-69$ & $\mathrm{Cl}$ & $\mathrm{n}$ & 130 & $2 \times 10^{16}$ \\
\hline $393-23$ & $\mathrm{Zn}$ & $\mathrm{p}$ & $30-90$ & $6 \times 10^{13}$ \\
\hline $507-81$ & $\mathrm{Cd}$ & $\mathrm{p}$ & $15-25$ & $2 \times 10^{15}$ \\
\hline
\end{tabular}


In this table we give the apparent mobility and carrier concentration, derived from Hall effect for one type of carrier :

$n=\frac{1}{R_{\mathrm{H}} e}, \quad \mu=\frac{R_{\mathrm{H}}}{\rho}$.

The data in table I thus only indicate the n- or p-type of the samples since eq. (1) does not hold quantitatively when the material contains both types of carriers which is the present case.

p-type samples have exhibited a remarkable beha- viour : Annealing above $400^{\circ} \mathrm{C}$ brings about an irreversible change to n-type, after only a few minutes. Table II shows the changes in measured mobilities and carrier concentrations for p-type InSe samples. The defects which are responsible for the type of the crystal have not been identified. It is not possible at the present time to discuss their nature even tentatively since the site and nature of impurity centers in InSe are almost wholly unknown. The significant feature in this annealing procedure is that it affords a possibility of making $\mathrm{p}-\mathrm{n}$ junctions without resorting to diffusion perpendicular to the layer plane.

Table II. - Evolution of the transport parameters of two substrates with annealing temperature.

Annealing

temperature ${ }^{\circ} \mathrm{C}$

-20
100
200
300
400
500

Sample no 393/23 (Zn)

$\begin{array}{lcc}\text { type } & \mu_{\perp} \mathrm{cm}^{2} / \mathrm{V} \mathrm{s} & c \mathrm{~cm}^{-3} \\ -\mathrm{p} & - & - \\ \mathrm{p} & 30 & 6 \times 10^{13} \\ \mathrm{p} & 15 & 10^{14} \\ \mathrm{p} & 10 & 4 \times 10^{14} \\ \mathrm{n} & 2 & 10^{16} \\ \mathrm{n} & 70 & 2 \times 10^{17} \\ & 80 & 3,5 \times 10^{17}\end{array}$

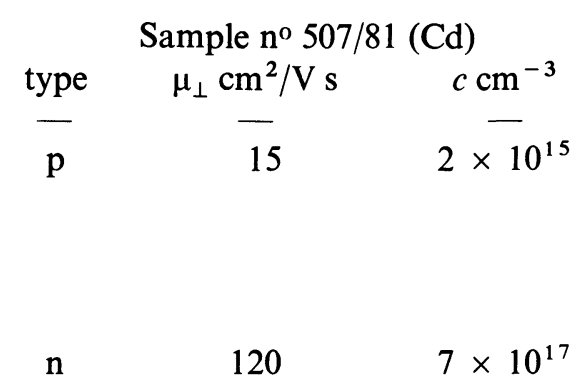

3. Transport of photoexcited carriers. - Transport parameters for photoexcited carriers are of course predominant as regards photovoltaic efficiency. The lamellar structure of InSe unfortunately makes the measurements quite difficult in the direction of the $c$-axis, except by indirect methods.

Lifetime measurements of majority carriers propagating in the plane of the layers were carried out by observing the decay of the photocurrent from $20 \mu \mathrm{s}$ light pulses. The longest lifetimes measured were $1.2 \mathrm{~ms}$ for n-type (364-11) samples and $0.2 \mathrm{~ms}$ for zinc-doped p-type crystals.

In the same geometry (light incident parallel to the $c$-axis) diffusion lengths were measured by the travelling spot method with photoconductive probes at the end of a long sample. The exponential dependence of the signal on the electrode-spot distance gives values of several hundreds of microns (Table III). Those values of transport perpendicular to the $c$-axis do indeed fit together and confirm the remarkable properties of majority carriers in the layer planes of InSe. Diffusion lengths parallel to the $c$-axis for n-type samples were determined by analysis of the photoconductive spectra of thick samples illuminated on the front surface, with two ohmic probes on the back.

Photovoltaic structures were made on several samples with different thicknesses along the $c$-axis. Dissymetry of the contacts was established with an annealed In-InSe contact (ohmic) and an unannealed In-InSe junction (rectifying) on the same side of the crystal which was then illuminated on the other side in the $c$-axis direction (Figs. 1 and 2), the two contacts

Table III. - Resume of transport properties of majority carriers in InSe at $300 \mathrm{~K}$.

\begin{tabular}{|c|c|c|c|c|c|c|}
\hline 1 & 2 & 3 & 4 & 5 & 6 & 7 \\
\hline - & - & - & - & - & - & - \\
\hline Sample $n^{\circ}$ & type & $\begin{array}{l}\text { Mobility } \\
\mathrm{cm}^{2} / \mathrm{V} \mathrm{s}\end{array}$ & $\begin{array}{l}\text { Lifetime } \\
\text { ms }\end{array}$ & $\begin{array}{l}L_{\perp}(\mu \mathrm{m}) \\
\text { calc. }\end{array}$ & $\begin{array}{c}L_{\perp}(\mu \mathrm{m}) \\
\text { meas. }\end{array}$ & $\begin{array}{c}L_{\|}(\mu \mathrm{m}) \\
\text { meas. }\end{array}$ \\
\hline $364 / 11$ & $\mathrm{n}$ & 500 & 1.20 & 1200 & 1000 & 24 \\
\hline $393 / 23$ & $\mathrm{p}$ & 90 & 0.24 & 200 & 400 & - \\
\hline
\end{tabular}

— Column 4 : lifetime measured by decay of photocurrent.

- Column 5 :

$L_{\perp}=\left(\frac{k T \mu_{\perp} \tau}{q}\right)^{1 / 2}$

was calculated for $T=300 \mathrm{~K}-\mu_{\perp}$ from column $3, \tau$ from column 4

- Column $6: L_{\perp}$ : travelling spot measurements.

- Column $7: L_{\|}$from best fit with photoconduction spectra (eq. (2)). 


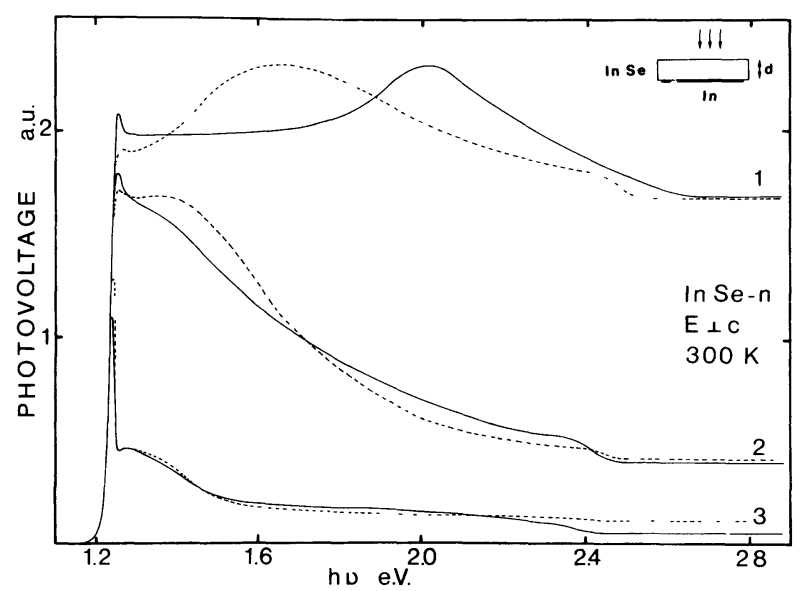

Fig. 1. - Photovoltaic response of $\mathbf{n}$-InSe-In structures (full line). $1: d=13 \mu \mathrm{m} ; 2: d=20 \mu \mathrm{m} ; 3: d=59 \mu \mathrm{m}$. Dashed lines are a fit with eq. (2) for $L=5 \mu \mathrm{m}$ (curves 1 and 2) and $L=9 \mu \mathrm{m}$ for curve 3 .

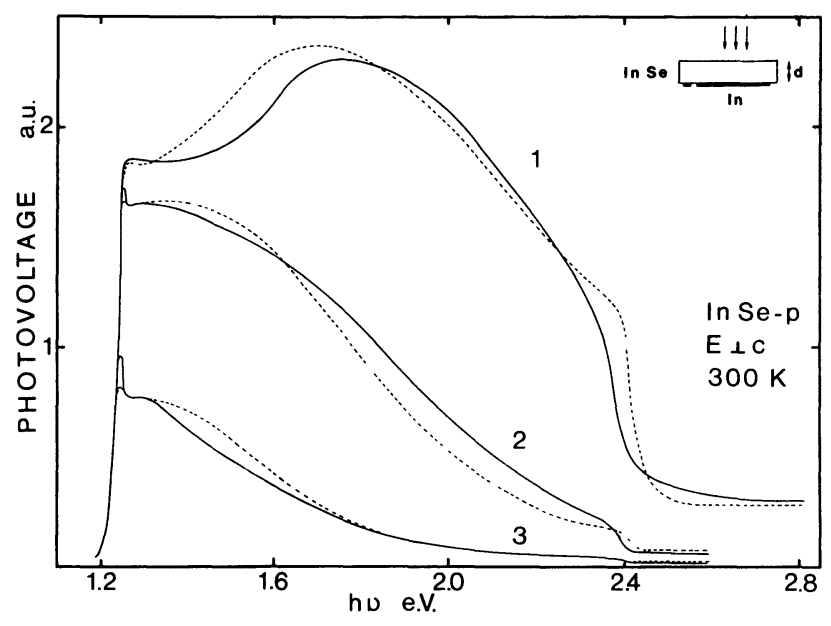

Fig. 2. - Response of p-InSe-In structures. $1: d=5.6 \mu \mathrm{m}$; $2: d=12 \mu \mathrm{m} ; 3: d=20 \mu \mathrm{m}$. Dashed lines are a fit with eq. (2) for $L=1 \mu \mathrm{m}, 1.7 \mu \mathrm{m}$ and $2.7 \mu \mathrm{m}$ respectively.

just serving as probes for the wavelength dependence of the number of photoexcited carriers reaching the back region. The photovoltaic signal is thus proportional (at constant incident photon flux) to the photocurrent

$P V \sim A I=q \varphi_{0} \frac{\alpha^{2}}{\alpha^{2}-\frac{1}{L^{2}}}\left[\exp \left(-\frac{d}{L}\right)-\exp (-\alpha d)\right]$

$A$ : a constant, $\alpha:$ the absorption coefficient, $I:$ the photocurrent, $\varphi_{0}$ : the photon flux, $L:\left(L_{\|}\right.$or $\left.L_{\perp}\right)$ diffusion lengths of carriers propagating parallel or perpendicular to the $c$-axis, $d$ : thickness of the sample. After correcting for reflection on both surfaces, a fit with this relation for several thicknesses (Figs. 1 and 2) gives $L_{\|}$between 5 and $9 \mu$ for undoped n-type samples and from 1 to $3 \mu$ for the zinc-doped substrates. The absorption coefficient used for the fit is that of reference [15]. In both cases, the apparent increase in calculated diffusion lengths with sample thickness is due to the presence of a perturbed surface layer with low diffusion length.

Finally, direct measurements of $L_{\perp}$ were made on samples with two faces cut parallel to the $c$-axis. On one of these faces, two probes were deposited and the sample was illuminated on the front face, with light incident perpendicular to $c$. The spectral dependence of the photovoltaic signal, with light polarized $E_{\perp} c$, fits with diffusion lengths between 50 and $100 \mu$. This value is certainly a minimum value since in the cutting procedure, surfaces are badly damaged and strained. Nevertheless this value is orders of magnitude higher than $L_{\|}$and confirms the high anisotropy of transport parameters in InSe.

4. Photovoltaic devices. - Two types of junctions have given satisfactory rectifying characteristics, and, consequently, significant conversion efficiency for bismuth p-type InSe structures and p-n InSe junctions.

4.1 Metal-SEMiconductor STRUCTURES. - We had noted from reference [13] that unannealed indium layers on n-type InSe give a measurable photovoltaic signal, with efficiencies in the range of 0.01 to $0.1 \%$. Low efficiencies were also found with $\mathrm{Cd}, \mathrm{Ag}$ and $\mathrm{Au}$ on n- or p-type material. Bismuth on p-type material was found to be the most efficient structure, and the fabrication procedure is as follows : $\mathrm{Bi}$ and In are deposited on each face of the sample and heated to $\sim 250^{\circ} \mathrm{C}$ under argon for several hours. Typical $I-V$ characteristics are shown on figure 3 . The rectifying side is provided by $\mathrm{Bi}$ and the indium contact is ohmic. Two types of such structures were made :

- indium grid/p-InSe/Bi film for illumination through the p-type substrate (indium side);

- semitransparent $\mathrm{Bi}$ layer/p-InSe/In for illumination on the $\mathrm{n}$-side (bismuth).

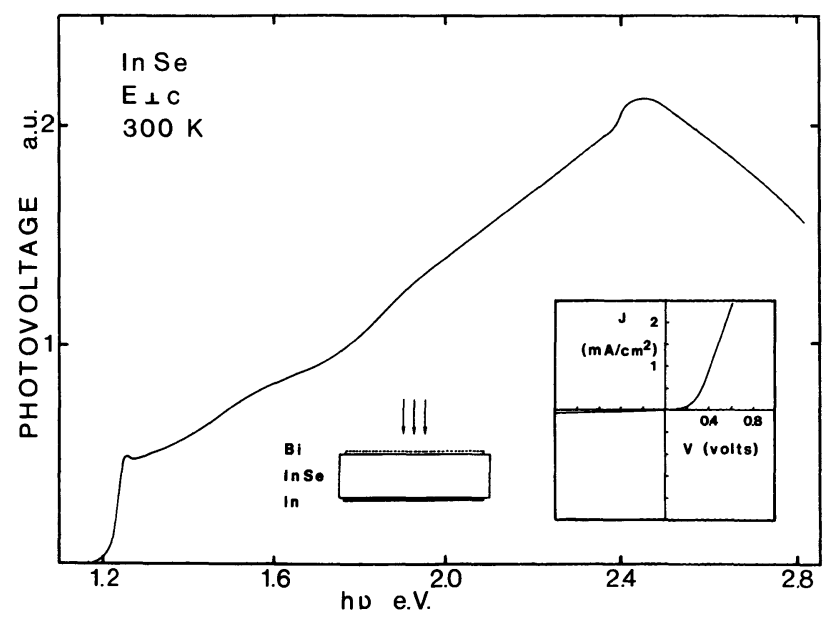

Fig. 3. - Photovoltaic response of a Bi-InSe-In structure. Illumination through the semitransparent Bi layer. Thickness of the substrate is $7 \mu \mathrm{m}$. Transparency of Bi layer is $20 \%$. Insert :I.V. characteristic of the junction. 
The first type of junctions has photovoltaic characteristics which are similar to those in figure 2 .

The second type of junctions, on the contrary, has a spectral shape which does not depend on the thickness of the substrate. This indicates that most of the carriers originate in the vicinity of the metal-semiconductor junction. We could make bismuth layers with transmittancies between 5 and $20 \%$ and the photovoltaic spectrum of such devices is given in figure 3 .

4.2 p-n Junctions. - Since p-type InSe reverts to n-type under heating, we fabricated junctions by establishing a thermal gradient parallel to the $c$-axis : one of the sides of the crystal is cooled by a refrigerated $\mathrm{Cu}$ block, the other being in contact with a flat plate heated to a temperature of $450^{\circ} \mathrm{C}$. Contacts were made with indium and silver lacquer on the $\mathrm{n}$-side. Electrical characteristics and photovoltaic spectra of those devices are given in figure 4. Here again, the spectrum shape depends little on the thickness of the p-type substrate when illuminated through the n-type layer. An acceptable fit (dashed line in figure 4) can be made with the experimental curve taking into account the contributions for the photocurrent from the $\mathrm{n}$-side region of width $D(2)$, the depletion layer, width $w(3)$, and the $p$ substrate (4),

$$
I_{w}=q \varphi_{0} \exp -(\alpha D)[1-\exp (-\alpha w)]
$$

and

$$
I_{\mathrm{p}}=q \varphi_{0} \frac{L_{\mathrm{p}}}{\alpha L_{\mathrm{p}}+1} \exp [-\alpha(D+w)]
$$

eq. (4) being valid for a substrate much thicker than $D+w$. The fit using figure 4 for a $18 \mu \mathrm{m}$ sample (dashed line) is for :

$D=0.75 \mu \mathrm{m}, \quad w=0.5 \mu \mathrm{m}, \quad L_{\mathrm{n}}=L_{\mathrm{p}}=2 \mu \mathrm{m}$.

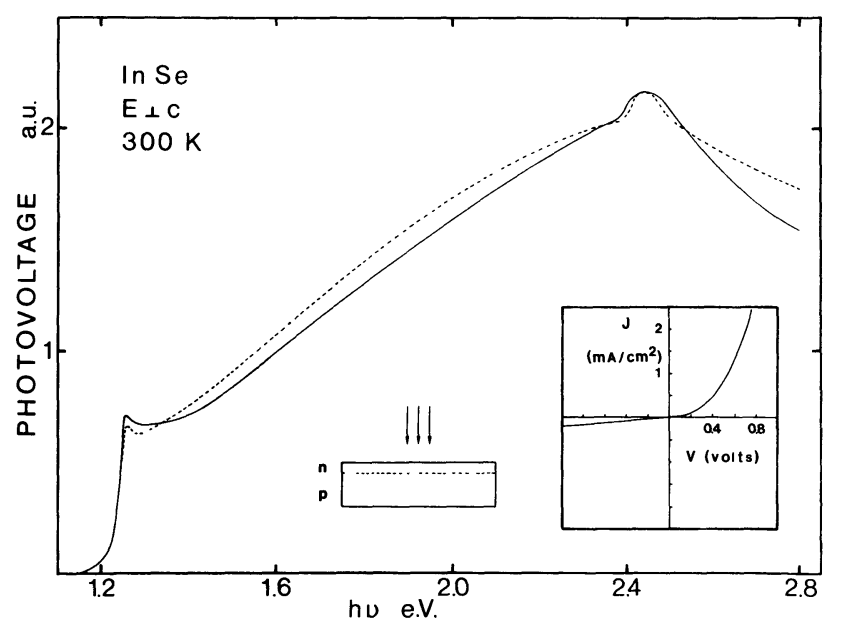

Fig. 4. - Photovoltaic response of a $\mathrm{p}-\mathrm{n}$ junction illuminated on the $n$-side. Total thickness is $18 \mu$. Dashed line is a fit with the sum of the contributions from the n-region (eq. (2)) the p substrate (eq. (4)) and the depletion zone (eq. (3)) with $D=0.75 \mu \mathrm{m}, W=0.5 \mu \mathrm{m}$ and $L_{\mathrm{p}}=L_{\mathrm{n}}=2 \mu \mathrm{m}$. Insert : Electrical characteristic of the diode.
Illumination through the p-type substrate gives spectra which are dominated by the thickness of the device and are analogous to those given in figure 2. This is again due to the poor transport properties of the p-type substrate.

5. Conclusion. - The conversion efficiency of our structures was roughly assessed to show the possibilities in using InSe.

No optimization of the cell thickness, or of optical characteristics was carried out, since the improvement due to those parameters is easily predictable, from the fundamental properties of the material.

Nevertheless, rather interesting efficiencies were measured in semitransparent Bi-InSe-In sandwiches, illuminated through the bismuth layer. We measured values of $1.3 \%$ under actual solar conditions without external cooling of the cells. The output power was measured as the maximum power dissipated in an external resistor. The Bi contacts that we used transmitted $20 \%$ of the incident light. The total efficiency of the heterojunction and substrate is thus about $6.5 \%$.

Homojunctions illuminated on the $n$-side have up to now given efficiencies of only $1.1 \%$ which is mostly due to the low mobility of the material that we used and to poor control of the junction profile.

Reverse current-voltage characteristics are given in figure 5 for illumination under $700 \mathrm{~W} / \mathrm{m}^{2}$ solar power density.

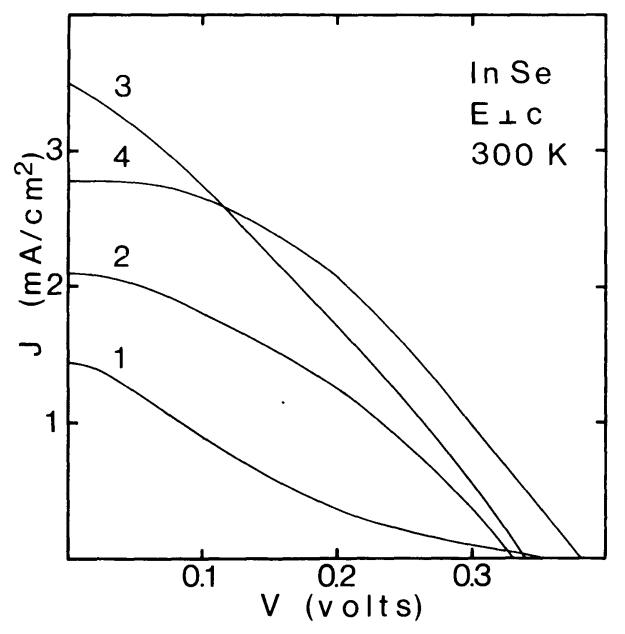

Fig. 5. - Electrical characteristics under $70 \mathrm{~mW} / \mathrm{cm}^{2}$ solar flux for representative junctions. Efficiencies are : $-\mathrm{Bi} / \mathrm{InSe} \mathrm{n}^{0} 1$ : $\eta=0.15 \% ; \mathrm{n}^{\circ} 2: \eta=0.4 \%$. p-n junctions $\mathrm{n}^{0} 3: \eta=0.5 \%$; $\mathrm{n}^{0} 4: \eta=0.6 \%$.

In both types of devices an improvement of the efficiency by a sizeable factor is attainable by standard methods :

- Reduction of the series resistance. The optimum thickness should be around 6-8 $\mu$ (on a reflecting metallic substrate to maintain a good optical collection rate). 
- Deposition of $\operatorname{In}_{2} \mathrm{O}_{3}$ layers which may serve as transparent rectifying contacts and antireflecting coating. (The refractive index of $\operatorname{In}_{2} \mathrm{O}_{3}$ is 1.7 , which matches that of InSe : 3.)

- Better control of the substrate material, as regards crystalline quality and impurity sites. This point is certainly preeminent : our structures were prepared from material that is undoubtedly very far from reflecting the intrinsic properties of InSe. In the same line, the p-n junction fabrication by a thermal gradient procedure leads to a junction the profile of which is far from abrupt. We used this method to demonstrate the feasibility of such devices but there is ground here for significant improvement.

- Finally, it is possible to take advantage of the good transport characteristics of the material for carriers propagating in the layer plane [16-18] by making diodes with the inversion layers in a plane parallel to the $c$-axis.

Acknowledgments. - This work was performed under contract P.I.R.D.E.S. $\mathrm{n}^{\mathrm{o}}$ 2546. We thank the S.A.T. company for measurements of some of our devices on their solar simulator facilities.

\section{References}

[1] Atakishiev, S. M. and Akhundov, G. A., Phys. Status Solidi 32 (1969) K33.

[2] Damon, R. W. and Redington, R. W., Phys. Rev. 96 (1954) 1498.

[3] Mori, S., Shigetomi, S. and Koga, Y., J. Phys. Soc. Japan 18 (1963) 308.

[4] Abdullaev, G. B., Guseinova, E. S. and Tagiev, B. G., Phys. Status Solidi 17 (1966) 593.

[5] Perš̀in, M., Č́lustka, B., Markovič, B. and Peršin, A., Thin Solid Films 5 (1970) 123.

[6] Imai, K. and AвE, Y., J. Electrochem. Soc. 123 (1976) 576.

[7] Kaziev, F. N., Sheinkman, M. K., Ermolovich, I. B. and Akhundov, G. A., Phys. Status Solidi 31 (1969) K59.

[8] Abdullaev, G. B., Alieva, M. Kh. and Mamedova, A. Z., Phys. Status Solidi 25 (1968) 75.

[9] Abdinov, A. Sh. and Kyazym-Zade, A. G., Sov. Phys. Semicond. 9 (1975) 1290.

[10] Abdinov, A. Sh. and Kyazym-Zade, A. G., Sov. Phys. Semicond. 9 (1975) 1113.
[11] Abdinov, A. Sh. and Kyazym-Zade, A. G., Sov. Phys. Semicond. 9 (1975) 1537.

[12] Voronyuk, P. I., Yakimova, A. S. and Kovalyvk, Z. D., Izv. Vuz. Fiz. 7 (1970) 120.

[13] Segura, A., Besson, J. M., Chevy, A. and Martin, M. S., Il Nuovo Cimento 38B (1977) 345.

[14] Chevy, A., Kuhn, A., Martin, M. S., J. Cryst. Growth 38 (1977) 118.

[15] Andriyashik, M. V., Sakhnovskit, M. Yu., Timofeev, V. B. and Yakimova, A. S., Phys. Status Solidi 28 (1968) 277.

[16] Fivaz, R. and Mooser, E., Phys. Rev. 163 (1967) 743.

[17] Schmid, Ph., Vortchovsky, J. P., Phys. Status Solidi (b) 65 (1974) 249.

[18] Kipperman, H. H. and Vermig, C. J., Nuovo Cimento 63B (1969) 29. 